\title{
Un análisis de las relaciones entre 'moral' y 'política' en un movimiento de demanda de justicia
}

\author{
Diego Zenobi* \\ ${ }^{*}$ CONICET, Facultad de Filosofía y Letras, Universidad de Buenos Aires, Argentina. \\ diegozenobi@yahoo.com
}

RMA

Antropología Social

\begin{abstract}
Resumen
En el presente trabajo sugiero que, a diferencia de cómo han abordado la cuestión algunas investigaciones sobre movimientos de familiares de víctimas, 'moral' y 'política' no deben ser tratados como universos autónomos y en conflicto. En cambio, sostengo que las actividades que los propios actores definen como políticas están moralmente informadas, esto es, están atravesadas por juicios morales y son productos de ese tipo de evaluaciones.

Para ello me baso en el material producido a lo largo de un trabajo de campo extendido realizado en el denominado 'movimiento Cromañón'. Así, me propongo analizar el proceso de creación y disolución de las 'asambleas de familiares de Cromañón', enmarcado en el contexto de las tensiones entre familiares politizados y no politizados. Sugiero aquí que las evaluaciones morales realizadas por los protagonistas del movimiento son un factor central para comprender el modo en que ellos orientan aquellas prácticas y situaciones a las que definen como políticas. A través de esos juicios ellos ponen en juego lo que consideran como correcto, deseable y, en virtud de ello, conveniente para su lucha.
\end{abstract}

Palabras Clave: familias, política, víctimas, movimiento Cromañón.

An analysis of the relationship between 'moral' and 'politic' in a justice demanding movement

\begin{abstract}
Unlike the way in wich some researchs on victim's relatives movements have addressed the relations between 'moral' and 'politics', in this article I suggest that they should not be treated as autonomous and conflicting universes. Instead, I argue that the activities that social actors define as 'politics', are morally informed, that is, are crossed by moral judgments and are products of such kind of assessments.

I draw on the material produced over extended field work carried out in the so-called 'movement Cromañón'. So, I will analyze the process of creation and dissolution of 'families of Cromañón assemblies', that took place in the context of tensions between politicized and non-politicized relatives.

I suggest here that moral evaluations made by social actors are a central key in understanding how they guide those practices and situations they define as politics. Through these kind of judgements they show what they consider proper, desirable and, under it, most suitable for their struggle.
\end{abstract}

Keywords: families, politics, victims, Cromañón movement.

En las últimas décadas nuestro país ha sido testigo de la aparición de numerosos reclamos de justicia (Pereyra 2005) impulsados por personas que se autodefinen como 'familiares de víctimas'. Dentro de ese particular universo, los organismos vinculados a la defensa y promoción de los Derechos Humanos conformados en su mayor parte por parientes de detenidos desaparecidos durante la dictadura militar argentina iniciada en 1976, conviven con un conjunto de expresiones surgidas más recientemente impulsadas por otros 'familiares'. Se trata de los familiares de víctimas de la violencia policial reunidos en la CORREPI y en la COFAVI (Pita 2010), de víctimas de accidentes de tránsito y de delitos 'comunes' nucleados en la Asociación Madres del Dolor (Claps 2007); de los familiares de los fallecidos en el atentado a la Asociación Mutual Israelita Argentina (AMIA) (Fischamn y Pelacoff 2002); también de los familiares de víctimas de hechos de 'inseguridad' que a diferencia del resto de los conjuntos nombrados, no han conformado un colectivo ni una organización institucionalizada (Kessler 2007; Schillagi 2006). En este contexto, en los últimos años el movimiento impulsado por los parientes de los 194 fallecidos en el incendio del local república Cromañón ocurrido en 2004, ha adquirido un importante protagonismo. ${ }^{1}$

\footnotetext{
1 El incendio se produjo en un recital de música rock en el que había entre 2700 y 3000 personas. El mismo fue producto del impacto de un fuego de artificio en el revestimiento acústico del lugar. La combustión de los materiales que cubrían el techo produjo un humo tóxico que rápidamente se extendió por todo el local generando dificultades para respirar en los asistentes. Muchos de ellos no pudieron encontrar a tiempo la forma de escapar de allí puesto que no había salidas de
} 
El trabajo de campo para mi tesis doctoral fue llevado adelante en uno de los grupos de familiares que conforman el denominado 'movimiento Cromañón'. A lo largo de tres años participé en sus reuniones, marchas y actividades en demanda de justicia. ${ }^{2}$ Entre los principales objetivos del movimiento estuvieron promover el juicio político al jefe de gobierno de la Ciudad de Buenos Aires, Aníbal Ibarra y la realización del juicio penal oral a los responsables penales por lo sucedido (cf. Zenobi 2014). ${ }^{3}$

Desde los primeros días en que los familiares de los fallecidos comenzaron a movilizarse, surgieron conflictos entre ellos alrededor de lo que algunos llamaban la politización de la lucha. La preocupación por la politización se vio expresada en la marcha conmemorativa de primer mes del incendio. De acuerdo con las crónicas, la misma contó con la presencia de más de 10.000 personas y se extendió a lo largo de siete cuadras. ${ }^{4}$ Los padres y madres de las víctimas estuvieron a la cabeza de la marcha. Algunos de ellos estaban encabezados por Pablo Asturias, padre de un fallecido y, al mismo tiempo, abogado de la mayoría de los familiares. Algunas semanas después ellos formarían el grupo Que No Se Repita (QNSR). A lo largo de la marcha, estos padres insistieron en que se evitaran los gritos y los cánticos alusivos a los responsables del incendio de República Cromañón puesto que veían en esas expresiones formas inadecuadas de manifestar el dolor y de demandar justicia. De un modo contrario, otro núcleo de familiares optó por utilizar un escenario montado en Plaza de Mayo frente a la Casa de Gobierno con el objetivo de hacerse escuchar. Mostrando su disconformidad con la situación el referente público del primer grupo señaló ante los medios de comunicación, que él y quienes lo acompañaban se retirarían de la marcha: "no vamos a seguir politizando el dolor, están haciendo política sobre el cadáver de nuestros hijos", ${ }^{5}$ dijo. En referencia a los padres que habían optado por manifestarse en el escenario declaró que estaban politizados y que estaban siendo manipulados por los partidos políticos de izquierda que los acompañaban.

Algunas investigaciones sobre los familiares de víctimas del incendio de República Cromañón, han sugerido que quienes consideraban que la lucha no debía politizarse impulsaban un tipo de reclamo "antipolítico" (Crivelli y Tufró 2009; Mauro 2009; Murillo 2008; San Cerbino 2009). La causa

emergencia habilitadas a tal efecto. La causa clínica de la gran mayoría de las muertes fue intoxicación con monóxido de carbono, a la que en algunos casos se sumó la quemadura de las vías aéreas superiores.

${ }^{2}$ A partir de aquí utilizaré cursivas para destacar las categorías propias de los actores.

3 Ibarra fue destituido en marzo de 2006 al ser considerado como el responsable político por la falta de controles adecuados de las normas de seguridad en los locales nocturnos de la ciudad. Por su parte, el juicio penal oral se llevó a cabo entre agosto de 2008 y agosto de 2009 y los acusados de ser responsables penales por la muerte de los 194 jóvenes corrieron distinta suerte. Con el correr de los años diversas instancias judiciales fueron modificando esas penas. Actualmente gran parte de ellos se encuentra en libertad, esperando la ratificación o rectificación de las condenas de prisión recibidas.

${ }^{4}$ http://www.pagina12.com.ar/diario/elpais/1-46822-2005-01-31.html

5 http://www.pagina12.com.ar/diario/elpais/1-46822-2005-01-31.html de ese carácter antipolítico, fue adjudicada a un proceso gradual a través del cual las interpretaciones de tipo moral sustituirían la esencia política de las demandas de justicia impulsadas desde la denominada 'sociedad civil'. Según se dijo, a lo largo de tales situación de protesta y reclamo,

"el concepto de ciudadano, núcleo de derechos, parece ser reemplazado sutilmente por el de 'víctima'. La trama económica y política (...) es leída en clave moral, y entonces es substancializada en nombres de políticos deshonestos (...) la lectura de la realidad política es obturada ideológicamente" (Murillo 2008: 334).

En este contexto, las consideraciones de tipo moral puestas en juego por los actores sociales son presentadas como un obstáculo para que ellos se representen adecuadamente su situación y reconozcan aquello que los analistas ven como el 'evidente' carácter político de su demanda. Desde esta perspectiva -como una variante de la tensión entre 'hechos' y 'valores'-, la moral se opone al hecho político, lo obtura, lo ocluye y desplaza. Así, 'moral' y 'política' son vistos como dos universos diferentes y en oposición.

Como consecuencia del impacto de algunos trabajos de Durkheim $(1951,1994)$ el estudio de la 'moral' (o las 'moralidades') ha sido largamente abordado desde la antropología social. En el ámbito internacional son numerosos los autores que han realizado relevantes aportes en las últimas décadas (Howell, 1997; Herzfeld 1988; Bezerra 1995; Texeira 1998). En el medio argentino fue Eduardo Archetti (2003) quien introdujo el interés por el tema, inspirando una serie de importantes y renovadores trabajos (Balbi 2000, 2007; Frederic 2004; Garriga 2006; Noel 2011), algunos de los cuales se ocuparon especialmente de abordar la importancia de la moral en la definición de quienes se presentan públicamente como familiares en demanda de justicia (Pita 2010, Vecchiolli 2009).

Continuando con el interés por abordar el papel de las moralidades en la acción social, entiendo que lo moral no debe ser considerado en términos sustantivos como un 'dominio' autónomo claramente diferenciado y opuesto a otros como 'la política'. Creo en cambio que debe ser tratado como una 'cualidad' o como una 'faceta' de las prácticas. Tal como afirma Firth "lo moral se refiere a las cualidades de los actos, más que a su sustancia" (1971:202). En particular, hablamos de un comportamiento relacionado con valores morales cuando nos referimos a acciones que revelan "la preferencia por determinados cursos de acción en función de su deseabilidad y obligatoriedad, siendo que esa preferencia es formulada conceptualmente y que la acción en su favor es estimulada a través de una carga emotiva adherida a su formulación conceptual" (Balbi 2007:76). ${ }^{6}$

\footnotetext{
6 Siguiendo el énfasis puesto por Durkheim en la importancia de los sentimientos, afectos y pasiones en la definición de lo moral, Firth (1971) sugirió que las consideraciones morales que fundamentan distinciones sociales son siempre concebidas "emocionalmente, (...) por más que se les dé una expresión intelectual y se los presente de una
} 
En el caso del movimiento Cromañón las posiciones conflictivas y en disputa en torno de la politización de la lucha, ponen en juego aquello que los actores consideran como lo correcto y deseable para su movimiento. A la vez, estas evaluaciones morales dan soporte al modo en que ellos definen qué es lo más conveniente para su interés de conseguir justicia; de esta manera, los criterios que definen la eficacia (o la ineficacia) de las acciones del movimiento están moralmente informados. En ese contexto, hacer lo correcto es visto como lo más conveniente. Esta adecuación entre valores e intereses se debe a que los actores ven aquello que los analistas llamamos 'sus intereses', en términos morales:

\begin{abstract}
"Esta superposición de valores e intereses desde el punto de vista subjetivo en nuestra propia conducta -la sutil forma en que una y otra vez confundimos lo que nos conviene hacer con lo que nos parece correcto hacer- es algo que todos hemos experimentado: el problema radica en entender cómo ello se produce" (Balbi 2007:72)
\end{abstract}

Orientado por estas ideas, lejos de considerar que lo moral es un dominio que impone un obstáculo para que los protagonistas del movimiento Cromañón se representen adecuadamente la realidad política de sus acciones, me propongo mostrar que las actividades que ellos mismos definen como políticas están moralmente informadas, esto es, están atravesadas por y son productos de evaluaciones morales.

En el presente trabajo analizaré la preocupación de los familiares de QNSR por la politización de su lucha y describiré sus inquietudes en relación a las reuniones de articulación hegemonizados por militantes y familiares politizados. Luego describiré cuál fue el remedio que ellos propusieron para evitarla. Se trata de las asambleas de familiares que se propusieron como la solución más legítima y eficaz. Concluyo con un análisis de politización como categoría local, sugiriendo que en este contexto la oposición a la politización no significa que los familiares tengan una posición 'antipolítica', oponiéndose y rechazando esa actividad ni que desconozcan el carácter político de sus acciones. Sugiero, en cambio, que politización es una categoría nativa movilizada en ciertos contextos que permite crear una oposición entre familiares a partir de una evaluación moralmente informada de las acciones de otros familiares.

\section{Familiares, militantes y politizados en las reuniones de articulación}

Los familiares de los fallecidos en el incendio de República Cromañón y los sobrevivientes del mismo comenzaron a

manera razonada" (op. cit.:202). En el mismo camino, al abordar el carácter moral del comportamiento social Archetti (2003) propuso que preguntarnos "de modo racional qué está bien, qué está mal no resulta suficiente; necesitamos enfocar nuestra investigación en lo que es deseable y meritorio para los actores" (op. cit.:163). movilizarse apenas unos días después del siniestro, pero el proceso a través del cual se fueron conformando diferentes grupos de actores llevó algunos meses. Así fue como con el paso del tiempo, los primeros vínculos de afinidad establecidos entre quienes se movilizaban en las calles, dieron vida a diferentes conjuntos. ${ }^{7}$ Si bien los grupos están integrados sobre todo por padres y madres de los fallecidos, en algunos de ellos también participan algunos militantes de partidos políticos y sobrevivientes del incendio. QNSR es el único espacio en el que no participan ni han participado orgánicamente sobrevivientes ni miembros de organizaciones y partidos políticos.

Hacia marzo de 2005 los miembros de esos grupos incipientes comenzaron a reunirse semanalmente en encuentros que se desarrollaban en sus sedes y que llevaban como nombre reuniones de articulación. Las articulaciones tenían como objetivo definir y coordinar las acciones públicas del movimiento $y$, en especial, todo lo relativo a la movilización que realiza el movimiento los días 30 de cada mes para conmemorar la fecha del incendio y demandar justicia. Participaban en ellas familiares, sobrevivientes y militantes que los acompañan en la lucha. A pesar de la intensa actividad y compromiso de quienes participaban en ese espacio, cabe destacar que siempre se trató de una minoría, conformada por entre diez y treinta personas como máximo. Entre los grupos de familiares, la participación de QNSR en articulación siempre fue irregular. Ello se debe a que sus miembros siempre tuvieron una serie de diferencias con el funcionamiento de ese espacio.

Al comienzo de una articulación los participantes se sientan en círculo y el moderador de la misma se encarga de conformar un temario con los puntos a debatir. Allí deciden qué banderas encabezarán la marcha, cuál será el recorrido y quienes participarán en el acto de cierre, entre otras cuestiones. También se ocupan de tender vínculos con otras luchas para evitar que, como dicen, 'Cromañón se vaya aislando'. Para ello promueven el vínculo con otras organizaciones y grupos a través de la difusión de petitorios, adhiriendo a los mismos, participando en actos de otras causas, en homenajes a víctimas de otras tragedias, etc. Estas decisiones relativas a la organización del movimiento se toman a través de un mecanismo al que sus participantes llaman 'por consenso'. Decidir por consenso implica que quienes promueven acciones divergentes o en conflicto buscan el modo de acordar y acercar esas posiciones contradictorias. Una vez que las personas que debaten consideran que hay un acuerdo o alguna de ellas cede en su posición, todos reconocen que se ha establecido un consenso. Las posiciones consensuadas entre quienes participan en ese espacio se ven reflejadas en el documento

\footnotetext{
7 Los grupos conformados son: Que No Se Repita (QNSR); Familias por la vida (también conocido como la ONG); Memoria y Justicia por Nuestros Pibes (también conocido como Paso por la calle de la ciudad en la que realizan sus reuniones semanales) y la Comisión de Familiares de Cromañón (CoFaCrom.). A mediados de 2005 este último grupo, se dividió y dio lugar a la Asociación de Padres de Hijos Asesinados en Cromañón (APHAC) por un lado, y a la Asociación de Víctimas de la Inseguridad Social en la Argentina (AVISAR) por el otro.
} 
que es leído en los actos de cierre de las marchas. De ahí que el nombre completo del mismo sea "Documento Consensuado entre familiares, amigos y sobrevivientes de la masacre de Cromañón".

Hacia junio de 2006 comenzó a discutirse en articulación la propuesta de establecer vínculos con organizaciones y colectivos de protesta para conformar un 'Movimiento contra la Impunidad'. En ese contexto se estableció la necesidad de crear una comisión de trabajo que tendría como objetivo tender puentes y coordinar actividades con otros movimientos de protesta y comenzar a participar orgánicamente en las luchas de otros familiares. Así fue como se decidió aceptar la invitación a participar en una marcha organizada por los familiares de un joven víctima de la violencia policial fallecido unos meses atrás. Asimismo en la reunión se decidió asistir a los actos del 26 de junio que recordarían la denominada 'masacre de Puente Pueyrredón' en la que fueron asesinados por la policía los militantes piqueteros Maximiliano Kosteki y Darío Santillán. Estas decisiones eran vistas por quienes participaban en articulación como muestras de solidaridad con otras luchas. Se trataba de una cuestión necesaria para que el movimiento también recibiera la adhesión de estos otros actores en demanda de justicia: "difícilmente logremos solidaridad hacia nuestra lucha, si no participamos de otras acciones importantes contra la Impunidad".

A contramano de las resoluciones tomadas en articulación como las señaladas más arriba, en varias ocasiones desde QNSR se cuestionó el establecimiento de vínculos con otras luchas. Mientras que para quienes participan en aquel espacio de decisión ese tipo de propuestas eran positivas para la lucha, para los integrantes de QNSR se trataba de propuestas politizadas negativas para el movimiento, que desvirtuaban el pedido de justicia.

Este tipo de acuerdos alcanzados en articulación considerados como nocivos para su propia demanda, son vistos desde QNSR como una consecuencia de la participación en ese espacio de militantes y de familiares a los que llaman politizados. En virtud de sus trayectorias políticas, de la cercanía con los militantes y del tipo de acciones que promueven, los miembros de otros grupos del movimiento son vistas como politizadas. Los familiares politizados aceptan a los militantes en sus grupos y al revés, los militantes se acercan a los grupos con familiares politizados.

Analía es sobreviviente del incendio y hermana de un joven fallecido en esa ocasión. Ella participa activamente de QNSR y trabaja como abogada en el estudio jurídico de Pablo Asturias, el referente de ese espacio que es, al mismo tiempo, padre de un fallecido y abogado de la mayoría de los querellantes. Para Analía, la lucha tiene un carácter político inevitable. Ella cree que la política forma parte de la demanda de justicia en la medida en que el incendio fue un producto de las decisiones de un Estado que debía controlar el correcto funcionamiento del local pero que no lo hizo a causa de la corrupción: "indudablemente el tema de la política no puede quedar al margen de lo que fue Cromañón, porque no solamente es un tema judicial. Inevitablemente tiene que ver con una cuestión política... porqué estaba habilitado el lugar (...)" (Entrevista a Analía, julio de 2009).

Al expresar la relación entre el incendio y la política, entiende que si bien la política forma parte de la lucha, "no hay que equivocarse en el rumbo, porque hay muchas personas que usaron el apoyo político que tuvimos para otras cosas que no tenían nada que ver con Cromañón, entonces uno tiene que tener bien en claro el límite..." (Ibídem.). Como cabría esperar, es justamente ese límite el objeto de las disputas entre familiares, familiares politizados y militantes. Para ella, quienes politizan Cromañón se comportan inadecuadamente al 'equivocar el rumbo' y usar la política para 'otros fines' que están más allá de la búsqueda de justicia.

A causa del papel preponderante de los militantes y de los familiares politizados en articulación, los integrantes de QNSR suelen decir con preocupación que allí 'se hace política' y que esas reuniones 'están manejadas por los partidos políticos'. Para ellos, los militantes y los familiares politizados responden a sus propios intereses políticos, que no coinciden necesariamente con los del resto del movimiento. Mientras que ellos tendrían intereses estrictamente políticos, el movimiento busca justicia, una cuestión esencialmente política pero que no tiene fines políticos. Por tal motivo frecuentemente expresan su preocupación con respecto al riesgo de que 'la lucha se politice', esto es, que sea 'usada' para que se cumplan objetivos que ellos ven como ajenos a su demanda.

En el contexto de las tensiones entre familiares, familiares politizados y militantes, los actores realizan evaluaciones morales que ponen en juego sus propios juicios acerca de lo correcto e incorrecto, lo deseable e indeseable en relación a cómo enmarcar sus acciones para la organización y la demanda pública. En tanto fundamento de las conductas, las nociones locales sobre lo correcto y lo incorrecto, deben ser estudiadas en las circunstancias precisas en las que se ponen en juego puesto que, como ha señalado Firth (1971), "las ideas sobre lo bueno y lo malo, tal como las interpretan los individuos al referirlas a sus propias situaciones particulares, otorgan una importante justificación a la acción social" (op. cit.: 229).

En resumen, mientras que algunos de los actores movilizados procuran actuar vinculando Cromañón con otras luchas y priorizan el vínculo con los militantes, otros ven en esta estrategia una forma reprobable de conducirse. Los primeros ven a los segundos como ingenuos y despolitizados, mientras que éstos consideran a aquellos como politizados y sostienen con preocupación que si bien su lucha es política, la misma no debe politizarse. Estos modos de evaluar la conducta permiten entrever la apelación implícita o explícita a postulados normativos según los cuales unos y otros ven a ciertas conductas como adecuadas y a otras 
como reprobables. La importancia de estos juicios sobre el comportamiento propio y ajeno reside en que los actores sociales se relacionan entre sí teniendo en consideración tanto el modo en que ellos mismos son evaluados por otros, así como las formas en que ellos mismos evalúan las acciones desplegadas por esos otros:

"(...) la conducta de un individuo tiende a ser guiada por los juicios concretos de los demás, por su expectativas de seguir mereciendo opiniones similares, pero también por sus propias valoraciones y por el reconocimiento de la validez que tendría el parecer de sus congéneres, de hallarse éstos en posición de juzgarlo" (Firth 1971:204).

Los familiares que se muestran preocupados por la posible politización del movimiento no cuestionan la presencia de militantes en las reuniones de articulación en las que se toman las decisiones más importantes. Consideran, en cambio, que tal presencia es 'natural' en el contexto de una lucha esencialmente política, y necesaria en virtud de que ellos acompañan a las víctimas. Por su parte, difícilmente podrían cuestionar la presencia de los familiares politizados debido a que ellos también son vistos como víctimas con todo el derecho a decidir sobre el movimiento. Debe comprenderse entonces que, para ellos, el movimiento no se ve politizado mecánicamente por la mera presencia de militantes o de familiares politizados. Desde su punto de vista la politización ocurre, en cambio, cuando se toman ciertas decisiones en articulación que afectan a la vida pública del mismo.

Desde QNSR creían que si hasta el momento los politizados habían logrado imponer sus posiciones ello se había debido al mecanismo empleado para decidir en articulación. En efecto, para ellos la toma de decisiones 'por consenso' representaba un problema puesto que, a causa de ese mecanismo, lo acordado en articulación no representaba a la 'mayoría de padres' que ellos veían como los protagonistas del movimiento. Aún cuando fueran una minoría numérica, los militantes y los familiares politizados lograban consensuar relevantes decisiones a través de las cuales influían negativamente en la lucha. Por este motivo desde QNSR se impulsó la propuesta de modificar la forma de tomar decisiones. Para ello propusieron la creación de una asamblea de familiares que sería el máximo órgano decisorio del movimiento, en el cual las decisiones se tomarían a través del voto nominal y no por consenso.

\section{Las asambleas de familiares}

Hacia mitad de 2006 los familiares de QNSR se acercaron a algunas reuniones de articulación para proponer la creación de un espacio alternativo a esas reuniones. El objetivo de crear una asamblea de familiares era, según plantearon, estimular la presencia de familiares en la vida pública del movimiento puesto que cada vez eran menos los padres y madres que se interesaban por participar en las movilizaciones y en esas instancias de decisión. También se propuso que, a diferencia de aquel espacio, la asamblea no funcionara en base al consenso alcanzado por unas pocas personas sino que las decisiones se tomaran por mayoría, a través del voto nominal. Los presentes en articulación coincidieron en que esta podía ser una forma de estimular la participación de familiares en la vida organizativa del movimiento. Una vez aprobada la propuesta, se decidió que mientras en articulación se debatirían las propuestas relativas a la marcha y las decisiones seguirían tomándose por consenso, la decisión final en relación a las mismas estaría reservada a la asamblea: 'articulación propone, asamblea decide', fue la consigna.

Al interior de QNSR todos sabían que la propuesta de crear la asamblea era producto de su preocupación por la politización del movimiento. La iniciativa se presentaba como un modo de lidiar con la hegemonía de militantes y familiares politizados que imponían su voluntad allí. Ellos estimaban que si en la instancia definitoria de la asamblea participaban muchos familiares y el voto era nominal, entonces sí se expresaría la voluntad de la 'mayoría de padres' y no el interés de los militantes y los politizados que eran una minoría. Si las cosas salían bien ellos no podrían continuar 'usando Cromañón' para sus propios fines políticos.

La primera asamblea se realizó en julio de 2006 en un lugar neutral, que no pertenecía a ninguno de los grupos. Se trataba de un salón ubicado en el subsuelo de una escuela de psicología social en el que se había realizado las primeras articulaciones. La iluminación provista por luz de tubos daba al lugar un aspecto frío. La distribución de los asistentes prefiguraba claramente las pertenencias grupales. Los familiares de QNSR eran unos treinta. Sumados entre sí, todos los integrantes de los otros grupos -la ONG, Paso, APHAC y AVISAR- no llegaban a igualar esa cantidad. En ese escenario QNSR, el grupo impulsor del encuentro, ocupaba casi la mitad del salón en el que la misma se desarrollaba.

A simple vista, las distinciones de clase y condición social también eran claras: QNSR agrupaba a los padres de clase media mientras que APHAC y, en cierta medida la ONG, estaban compuestos mayormente por personas de origen humilde. Estas distinciones no sólo eran evidentes para mí. La primera intervención fue la de un hermano de la ONG quien señaló que "no tenemos que hacer diferencias si 'soy de la ONG' o de Asturias. No tiene que ser que porque uno tiene un departamento en Villa del Parque y otro en Matanza o zona Sur nos miremos diferente... somos diferentes pero nos pasó lo mismo". Pablo 'recogió el guante' y apoyando esas palabras enfatizó la riqueza y vitalidad que suponía para el movimiento la convivencia de diferentes formas de manifestarse y actuar públicamente. En esa ocasión el señaló que "en la diferencia está la riqueza. A unos grupos se les ocurren ciertas cosas y se expresan de cierta manera, y nosotros [QNSR] lo hacemos de otra".

Si bien nadie había prohibido la participación de los militantes ellos parecieron haber entendido la idea de una 
'asamblea de familiares': apenas habían asistido unos siete u ocho de ellos. La cantidad de militantes que participaban en articulación habitualmente no era mucho mayor pero frente al gran número de familiares presentes en esta ocasión, en franco contraste con lo que ocurría en aquel otro espacio, aquí pasaban desapercibidos. En este nuevo contexto los militantes mantuvieron una actitud pasiva y no intervinieron en los debates.

Las cuestiones planteadas en la asamblea estuvieron relacionadas con el recorrido de la próxima marcha, las banderas que la encabezarían y la realización de un homenaje a los chicos, entre otras cuestiones menores. En esta ocasión no hubo mayores conflictos entre los presentes y todos coincidieron en las propuestas realizadas. A lo largo de las votaciones relativas a definir esos temas, los militantes no se pronunciaron. Por su parte, si bien algunos politizados mostraron su disidencia a través del voto, ellos eran una pequeña minoría. Así fue como la 'mayoría de padres' logró imponerse en todas las decisiones. Sobre el final de la reunión desde QNSR se mostró satisfacción con la convocatoria puesto que la primera asamblea no había sido 'manejada' por los militantes ni por los politizados.

Un mes después, en agosto de 2006, se realizó la segunda asamblea. A diferencia de lo que ocurrió en el primer encuentro, en esa ocasión surgieron algunas diferencias importantes que generaron tensiones. En principio, se produjo un debate alrededor del momento en que debía ser leído el documento consensuado en articulación en la próxima marcha del día 30. La asamblea debía ratificar o rectificar lo propuesto en articulación, espacio desde el que se había consensuado leer el documento al principio de la movilización y dejar para el final la lectura de los nombres de las 194 víctimas del incendio. Los miembros del grupo Paso a quienes en QNSR llamaban politizadas, explicaron que en articulación se había consensuado eso porque si el documento se dejaba para el final, muchos familiares no lo escucharían puesto que se retirarían de la concentración una vez leídos los nombres de los chicos. QNSR se opuso a ese orden. Sus miembros argumentaban que los nombres debían leerse antes que el documento, justamente, para que todos los escucharan. Para unos y otros el orden de precedencia reflejaba el lugar que debía ocupar la política en la marcha. Los padres de QNSR creían que leer el documento primero era un símbolo de 'la política' imponiéndose sobre algo que la trascendía, como era la lectura de los nombres de sus hijos fallecidos.

Una discusión del mismo tono volvió a repetirse un rato más tarde al tratar la ubicación de las banderas en la marcha. Una de ellas era de color negro y tenía escrita en grandes letras blancas la palabra 'Justicia'. La otra era una bandera argentina sobre la cual estaban pegadas las fotos de los rostros de los 194 jóvenes fallecidos en el incendio. Para una madre, de la ONG, la bandera con la inscripción 'Justicia' debía estar al frente de la columna mientras que para los familiares de QNSR la bandera que debía ir adelante era aquella con la foto de las 194 víctimas. Ellos decían que 'los chicos siempre tiene que estar primero', por lo que poner al frente de la movilización la bandera con la inscripción significaba dar más importancia a la lucha que a los chicos. Luego de varios intercambios y con el objetivo de dirimir qué caminos tomar, se procedió a votar sobre ambos temas considerando todas las propuestas realizadas. En ambas circunstancias se impuso la postura de QNSR. Una vez más, los pocos militantes presentes no participaron de la votación ni intervinieron en las discusiones, reservando esas prerrogativas para los padres. Los familiares politizados por su parte, fueron nuevamente una pequeña minoría. Dos meses después de este encuentro, se realizó la siguiente asamblea que sería la última.

El encuentro siguiente era particularmente importante para los integrantes de QNSR. Ellos pretendían poner en debate cuáles debían ser las prerrogativas de los militantes en la toma de decisiones en el marco del movimiento. Cabe recordar que si bien hasta el momento los militantes no habían participado en las votaciones de las asambleas, ello se debía a su propia decisión personal, puesto que al acordarse en articulación la adopción del mecanismo de las asambleas, ese tema no se había discutido. Por otra parte, en articulación continuaban teniendo una gran influencia. Si bien el movimiento debía aceptar la participación de la mayor diversidad de actores ellos creían que quienes no fueran familiares de los fallecidos sólo debían acompañar las decisiones que éstos tomaran. En este contexto, ser familiar configuraba una condición más legítima que otras para decidir las cuestiones relativas a la lucha.

Al llegar al salón ese día encontré a Pablo Asturias conversando amigablemente con un militante. Me llamó la atención que casi no hubiera familiares de APHAC, apenas dos o tres de la ONG y sólo uno de Paso. No estaban las referentes de estos dos grupos. En cambio, al igual que en las reuniones previas, había unos treinta miembros de QNSR. Una vez dispuestos los cuarenta familiares asambleístas para dar comienzo al evento, la primera de las intervenciones fue la de un padre APHAC, quien dijo:

"yo vengo a comunicar que APHAC decidió que no va a participar más de la asamblea. Creemos que no se decide levantando la mano. Hace dos años que nos conocemos y tenemos diferentes maneras de luchar y no las vamos a resolver hoy. Vamos a participar en todas la acciones. Somos como somos. Nosotros venimos de dónde venimos. Es como un árbol que creció torcido durante años: ya no lo podés enderezar aunque quieras. Nosotros creemos muy poco en la justicia. Respeto a quien sí cree y también a los que van a la Iglesia ¡Pero yo desde que perdí a mi pibe no creo más! En articulación nos podíamos poner de acuerdo debatiendo. Ahi se hacen cosas buenas y malas. Se discute y se llega a acuerdos. Acá si traigo más gente gano. No hace falta traer el jardín de infantes para votar... 
Nosotros como APHAC estamos con todos: yo estoy con todos. Pero nadie manda a nadie. De dos años a acá no nos dimos un debate: que pensamos muy diferente. Y es así. No es el momento de debatir. Yo más de una vez tiré una piedra o me pelié con alguien. No creo en la justicia y lo haría de nuevo. En las marchas de los 30 igual vamos a estar presentes".

Las palabras de Gustavo reflejaban que había formas diferentes de luchar que, según el señalaba, eran irreconciliables. Estaban quienes luchaban pero creían muy poco en la institución judicial y sus mecanismos para administrar justicia, y había quienes ponían todas sus esperanzas en tales procedimientos. A su vez, como representante de su grupo, él manifestó su disconformidad con el nuevo mecanismo de toma de decisiones que se basaba en el voto nominal. De ahí que expresar su preocupación por el hecho de que "si traigo más gente gano".

Esta intervención tomó de sorpresa a los miembros de QNSR. Luego de estas palabras la madre de un sobreviviente que participaba en la ONG agregó que en el encuentro anterior se habían ido muy lastimados por lo que veían como "agresiones" entre familiares y que ellos no tenían intenciones de pelear con los padres de QNSR. Si bien yo no había estado presente en esa asamblea previa -la tercera-, algunos padres me comentaron que en esa ocasión se había responsabilizado a ese grupo por una actividad pública (una vigilia en Plaza de Mayo) que había fracasado. Entonces la madre del sobreviviente anunció que la ONG también dejaría de asistir a la asamblea. Sin embargo, al igual que el padre de APHAC que había hablado antes, señaló que su grupo estaba dispuesto a continuar asistiendo a la articulación. Finalmente, un padre del grupo Paso apoyó esa postura y señaló que si se retiraban dos grupos no tenía sentido continuar participando de la asamblea. Él también rescató la importancia de articulación como un espacio en el que se privilegiaba el consenso en lugar del voto nominal. Se trataba de un mecanismo para tomar decisiones que, según dijo "tiene en cuenta a todos los padres".

Toda la situación tomó de improviso a los miembros de QNSR. En ese contexto Pablo Asturias sostuvo:

"en asamblea se decidió poner la bandera con los nombres de los chicos delante de la marcha, se decidió leer los nombres antes que el documento y hacer la asamblea cada un mes. Y no se quieren respetar esas decisiones. El problema es que se antepone el interés personal a los intereses del grupo. Se decidieron cosas muy sencillas pero quedó evidenciado que no las decidieron ellos".

Mientras Pablo hablaba mirando a los compañeros de su propio grupo, el resto se iban levantando de sus asientos y procedían a retirarse. La última asamblea se iba disolviendo.

\section{El debate sobre el surgimiento y la disolución de las asambleas}

Los miembros de QNSR se reúnen semanalmente con el objetivo de informarse acerca de la causa penal abierta luego del incendio y para debatir e intercambiar opiniones acerca de la organización de las actividades públicas de demanda de justicia que impulsa el movimiento. Las reuniones se realizan en un local facilitado por una organización católica, ubicado en el centro de Buenos Aires. Se trata de un amplio salón en el que hay colgados dos cuadros de Juan Pablo II y algunas banderas con los colores del Vaticano. Además el lugar está ocupado por unas 50 sillas plásticas ubicadas de frente a una enorme mesa de roble desde la que suele hablar Pablo Asturias, el referente público del grupo.

Antes de comenzar las reuniones, a medida van ingresando familiares, se van conformando pequeños grupos de tres o cuatro personas que charlan entre sí. Los hombres por un lado, las mujeres por el otro, en la mayor parte de los casos se trata de matrimonios. Hasta el comienzo del encuentro todos charlan sobre temas diversos que no están necesariamente vinculados a la causa penal ni al movimiento. Entre quienes componen esos grupos de afinidad, algunos han establecido vínculos de amistad y suelen encontrarse entresemana para salir a cenar o a pasear juntos los fines de semana.

En una de estas reuniones se debatió la situación ocurrida en el marco de la última asamblea de familiares. Pablo Asturias fue el primero en intervenir e intentó alentar a que se expresaran sus compañeros de grupo puesto que, según dijo, no quería condicionar sus opiniones. En general, las primeras intervenciones se propusieron rebatir el argumento dado por el padre de APHAC que había señalado que las formas diferentes de luchar hacían imposible la participación en un espacio común como lo era la asamblea. Quienes criticaron este argumento señalaron que las formas diversas de expresarse públicamente habían convivido de un modo más o menos tensionado por el período de dos años en el marco del movimiento sin que ello terminara en una ruptura. De hecho, al principio de la primera asamblea Pablo Asturias y un miembro de la ONG se habían referido justamente a esa diversidad señalándola como una cuestión positiva.

Para la gente de QNSR, la verdadera causa de la ruptura estaba en que los militantes y los familiares politizados que hasta el momento habían hegemonizado la toma de decisiones en articulación, habían perdido esa prerrogativa al constituirse las asambleas. Ello se debía a que el nuevo sistema de toma de decisiones empleado en las asambleas, había sincerado las cosas. Según ellos, en esos grupos politizados había pocos familiares y muchos militantes y sobrevivientes que los acompañaban pero que, al no haber asistido a las asambleas, no habían sumado votos para sus propuestas. Así fue como los politizados habían quedado en minoría evidente y, por tal motivo, habían abandonado el nuevo espacio. Según se dijo en la reunión, esto había 
quedado claro cuando Gustavo se mostró disgustado con el hecho de que el grupo que contara con más votos impusiera sus decisiones.

Entonces se habló de la gente de Paso y se dijo que ellos habían sido los ideólogos de la ruptura. ${ }^{8}$ En ese contexto, un padre al que todos escuchaban afirmó que los miembros de ese grupo lograban 'llevar' a los demás aprovechándose de su experiencia política. Además se dijo que ese grupo sumaba militantes a las reuniones de articulación con el objetivo de imponer sus propuestas políticas. Sin embargo, a partir de la implementación de las asambleas ya no había podido continuar con sus intenciones puesto que en ese espacio, la 'mayoría de padres' que reivindicaba QNSR se había impuesto en las decisiones más importantes. Para todos, este era el motivo de que los politizados hubieran abandonado la asamblea. Debido a que habían perdido poder, ahora ellos querían volver a centrar las decisiones en el marco de los consensos de articulación, con el objetivo de volver a hegemonizar las definiciones sobre los caminos que debía seguir el movimiento.

En la reunión, todos los padres y madres de QNSR coincidieron en que la propuesta realizada por QNSR para crear las asambleas de familiares tenía su fundamentación última en una 'cuestión de poder'. En efecto, el modo en que se tomaban las decisiones era considerado como una cuestión política central puesto que permitía definir si la lucha respondería a los intereses de unos pocos militantes y familiares politizados o a los intereses políticos del conjunto de los familiares que buscaban justicia. En relación a esto, todos creían que era naturalmente deseable que en las instancias de decisión del movimiento se impusieran las propuestas de ese QNSR puesto que ellos eran todos padres:

\footnotetext{
"acá somos todos padres. En la articulación estábamos en desigualdad. El pensamiento de un partido político no puede votar igual que un padre porque no tiene mi dolor. Un sobreviviente puede ser... porque perdió un amigo... pero la articulación estaba llena de políticos".
}

Si bien el intento por imponer el voto nominal de los familiares a través de las asambleas había sido motivado por una cuestión política o de poder, esto no fue visto como una 'estrategia' o una 'manipulación' de parte de QNSR. En cambio, todos vieron ese intento como algo naturalmente correcto puesto que para ellos las decisiones debían ser tomadas por la 'mayoría de padres' y no por una minoría de politizados, militantes y sobrevivientes. Desde este punto de vista, ser familiar y no estar politizado configuraba una

\footnotetext{
${ }^{8}$ Años después, conversé con la referente de Paso sobre este episodio y se sorprendió amargamente por la interpretación según la cual la ruptura había sido promovida por su grupo. Me dijo que luego de ver que dos grupos habían decidido retirarse de ese espacio, los miembros de Paso presentes en esa ocasión habían decidido apoyar la decisión. Me contó que su ausencia ese día se había debido a un problema de salud de su hija que vive en el interior del país y a quien tuvo que asistir. Más allá de cuál haya sido la causa de esa ausencia, aquí me interesa destacar la interpretación política que se le dio a la misma.
}

condición más legítima que otras al momento de tomar las decisiones sobre el movimiento. A la vez que fue considerada como una cuestión correcta, el intento por imponer la voluntad de los familiares no politizados fue visto como lo más conveniente para la lucha puesto que así lograrían poner el interés político de justicia del conjunto por sobre los intereses políticos de unos pocos. Desde su propio punto de vista, hacer lo correcto era, a la vez, lo más conveniente para el movimiento.

Si la voluntad de QNSR debía tener preponderancia en el marco de la toma de decisiones, ello se debía a que mientras que el resto de los grupos representaban intereses parciales, éste era el grupo que representaba la diversidad al interior del movimiento: "nuestro grupo representa a todos: acá hay de todo, el que vive acá o allá, judiocatólico, izquierda/derecha. Los otros grupos son zonales [en referencia a APHAC] o ideológicos [en referencia a Paso y AVISAR] o están atrás de una líder [en referencia a la ONG]". Para sus miembros, a diferencia de los otros grupos que representaban a sectores sociales específicos, QNSR expresaba la heterogeneidad dentro del movimiento. Finalmente, luego de una larga discusión que incluyó una acusación pública al antropólogo señalándolo como un posible espía (Zenobi 2010), en la reunión de QNSR se impuso la decisión de dejar de participar en articulación por un tiempo, pero continuar participando junto al resto en la marcha con el objetivo de evitar la ruptura del movimiento.

\section{Algunas reflexiones sobre las relaciones entre 'moral' y 'política'}

El rechazo de parte de los familiares a la politización de su lucha fue tratada como un efecto de los "prejuicios hacia los partidos que orientaron correctamente un reclamo que no podía no ser 'político'" (Sanz Cerbino, op. cit.: 360). Estos prejuicios contra las expresiones de la política, se nos dice, condujeron a una suerte de moralización que se orientó a "despolitizar la voz de la sociedad civil" (Murillo 2008: 156). Así, desde una perspectiva preocupada por lo que 'debería ser pero no es', los familiares de las víctimas del incendio fueron definidos a partir de la carencia de herramientas conceptuales adecuadas para pensar su realidad. Sus intervenciones fueron tratadas como "una reducción de lo político a lo moral" (op.cit: 299). Desde esta perspectiva analítica los 'valores' morales no tienen valor cognitivo sino que, por el contrario, los mismos son un obstáculo para el pensamiento y la reflexión adecuada sobre los 'hechos'. De un modo diferente, en este trabajo he sostenido que la evaluación moral de las acciones de los protagonistas del movimiento Cromañón es un factor central para comprender el modo en que ellos orientan sus acciones, inclusive a aquellas a las que definen como políticas.

Como he intentado mostrar, las posiciones conflictivas y en disputa en torno de la politización de la lucha condujeron tanto a la conformación del espacio de las asambleas de familiares como a su disolución. En este contexto, 'politización' es un término que exhibe el modo en que 
algunos familiares hablan de otros familiares que, según dicen, se valen de la política para satisfacer sus propios fines políticos y no como un medio para conseguir justicia. Las acciones y propuestas que impulsan quienes se han acercado peligrosamente a modos de actuar que son sancionados como inadecuados, son evaluadas moralmente de un modo negativo; las mismas son vistas como espurias, respondiendo a intereses sectoriales o partidarios que ellos intentarían imponer con el objetivo de sacar provecho de la lucha. En ese contexto del movimiento el uso de la categoría 'familiar politizado' tiene un fin muy concreto, y está destinado a operar un efecto: quien moviliza esa categoría para señalar a otro familiar, pretende provocar en su auditorio una consideración negativa de quien es imputado de tal manera. Al modo de un acto perlocucionario, su uso pretende alcanzar "ciertas consecuencias o efectos sobre los sentimientos, pensamientos o acciones del auditorio o de quien emite la expresión o de otras personas" (Austin 1962: 145). A su vez, el uso de tal expresión está profundamente vinculado con la situación y con los participantes envueltos en la misma, puesto que, tal como señala Malinowski "cada enunciación verbal que hace un ser humano tiene la finalidad o función de expresar algún pensamiento o sentimiento efectivo en ese momento y en esa situación, y que por una u otra razón, es necesario hacer conocer a otra persona o personas" (1964:321). De esta manera, en el contexto del movimiento Cromañón, la expresión 'politización' denota una oposición entre familiares. En efecto, algunos miembros del movimiento Cromañón en determinadas situaciones pueden estar más cerca de los militantes y sus organizaciones que de otros familiares que los ven como politizados. Parece expresarse entonces una lógica según la cual, como ha analizado Vecchioli para el caso de los familiares de detenidos-desaparecidos, una determinada categoría "aproxima a individuos y grupos que ocupan posiciones aparentemente antagónicas y que separa a individuos y grupos que ocupan posiciones aparentemente idénticas" (Vecchioli 2004:12). Así es como a través de la manipulación de consideraciones y evaluaciones de tipo moral sobre ciertos familiares, se promueve la conformación de distinciones en el campo de relaciones sociales analizado. La distinción entre familiares politizados y no politizados es una importante frontera que resulta tan relevante para comprender la construcción de posiciones en el movimiento, como aquella que separa a familiares de políticos y que es frecuentemente enfatizada en los análisis del caso.

Para los familiares de QNSR la propuesta de armar la asamblea de familiares para desafiar a los politizados fue una cuestión política, de poder. Todos vieron en ese intento un esfuerzo por imponer un mecanismo de toma de decisiones que permitiera imponerse sobre los politizados. Esto fue considerado como lo correcto y deseable en términos morales en virtud de que quienes pasaban a tomar las decisiones eran los familiares no politizados. Al mismo tiempo esto fue percibido como lo más conveniente para defender sus propios intereses puesto que ellos podrían tomar las decisiones más adecuadas para el movimiento. Así, a lo largo de los conflictos suscitados durante el proceso de conformación y ruptura de las asambleas, los actores pusieron en juego aquello que consideran como lo correcto y adecuado y, en virtud de estos atributos, más conveniente para su lucha. El proceso de conformación y disolución de la asamblea de familiares muestra que, para ellos, 'hacer lo correcto' era 'lo mejor'. En tal sentido, los criterios a través de los que ellos definieron la eficacia (o la ineficacia) de sus propias acciones públicas estuvieron moralmente informados. Siguiendo a Balbi, en este caso puede verse que desde el punto de vista de los actores, aquello que los analistas reconocemos como 'valor' e 'interés' "no sólo no están necesariamente opuestos sino que tienden a superponerse, y aún a confundirse, porque los términos en que concebimos nuestros intereses son, desde un primer momento, términos morales" (Balbi 2007:76).

Siguiendo estas ideas, considero que desde la perspectiva que aquí me orienta es posible repensar la distinción analítica entre acciones basadas en 'valores' y acciones estratégicas basadas en el 'interés', frecuentemente reproducida desde las ciencias sociales. En principio, cabe destacar que tal operación de diferenciación entre esos 'tipos' de acción, expresa una atribución de estados internos a los actores que resulta problemática para el análisis sociológico. En diálogo con ciertos autores que se han ocupado de este tema (Herzfeld 1988, Needham 1972), Balbi (2007) ha sugerido que si bien resulta inevitable que los analistas atribuyamos estados internos a los sujetos con los que trabajamos, resulta necesario evitar estructurar los análisis a partir de la misma. Si consideramos que aquella fuerte distinción analítica entre tipos de acción no es percibida del mismo modo por los actores, el énfasis en la reconstrucción de las perspectivas locales se presenta como una alternativa para superar tanto aquella rígida dicotomización, como la atribución de 'estados internos' que la misma supone. En efecto, si se acuerda en que los actores ven aquello que los analistas llamamos 'sus intereses' en términos morales, entonces desde su propio punto de vista práctico, 'moral' y 'estrategia' no constituyen dimensiones del comportamiento opuestas o antitéticas. Resulta coherente entonces que procuremos evitar estructurar nuestros trabajos que se proponen dar cuenta del modo en que ellos perciben y construyen sus universos sociales, a partir de una oposición dicotómica estricta entre esas dimensiones. El trabajo en base a un abordaje etnográfico preocupado por analizar los fines con que son movilizadas ciertas categorías moralmente informadas, puede colaborar a alcanzar tal objetivo.

Buenos Aires, 25 de Marzo de 2013

\section{Bibliografía}

Archetti, E. 2003. Masculinidades. Fútbol, tango y polo en la Argentina. Antropofagia, Buenos Aires.

Austin, J. L. 1962 Cómo hacer cosas con palabras. Madrid, Paidós.

Balbi, F.A. 2007. De leales, desleales y traidores. Valor moral $y$ concepción de política en el peronismo. Antropofagia, Buenos Aires. 
Balbi, F.A. 2000. Interdependencia, Memoria Institucional y Valores Morales: Fundamentos Sociales de la Moralidad en una Coorperativa de Pescadores Entrerrianos. Avá. Revista de Antropología, 2: 76-94

Bezerra, M. 1995. Corrupção. Um estudo sobre poder público e relações pessoais no Brasil. Relume Dumará, Rio de Janeiro.

Claps, L. 2007. "Representaciones y discursos sobre la violencia presentes en la sociedad civil organizada: los casos de Cofavi y Madres del dolor". Ponencia presentada en XI Jornadas Nacionales de Investigadores en Comunicación. Mendoza, Argentina.

Crivelli, N., M. Tufró 2009. La Política como frontera. Un análisis de las formas de construcción de identidades al interior del Movimiento Cromañón. Revista Question, $n^{\circ} 22$. http://perio.unlp. edu.ar/question/numeros_anteriores/numero_anterior22/ensayos. html (Última consulta: 12/07/2012)

Durkheim, E. 1951. Sociología y filosofía. Guillermo Kraft, Buenos Aires.

Durkheim, E. 1994. La división del trabajo social. Planeta-Agostini, Barcelona.

Firth, R. 1971. Criterios morales y organización social. Elementos de Antropología social. Cap. 6, 201-232, Buenos Aires, Amorrortu.

Fischman, F., J. Pelacoff 2002. "Demandas de Justicia y marcas de identidad: manifestaciones públicas de los judíos de Buenos Aires después del atentado a AMIA". Ponencia presentada en The 11th International Research Conference of The Latin American Jewish Studies Association. Río de Janeiro, Brasil.

Frederic, S. 2004. Buenos vecinos, malos políticos: moralidad y política en el Gran Buenos Aires. Buenos Aires, Prometeo Libros.

Garriga, J. 2006. Haciendo amigos a las piñas. Violencia y redes sociales de una hinchada del fútbol. Prometeo, Buenos Aires.

Herzfeld, M. 1988. The poetics of manhood: contest and identity in a cretan mountain village. Princeton University Press, Princeton.

Howell, S. (Ed.) 1997. The ethnography of moralities. Routledge, London and New York.

Kessler, G. 2007. Miedo al crimen. Representaciones colectivas, comportamientos individuales y acciones públicas. Ed. Isla Alejandro En los márgenes de la ley, Cap.3, 57-73, Paidós, Buenos Aires.

Malinowski, B. 1964. El problema del significado en las lenguas primitivas. Ed. Ogden, C.K. y Richards, A.I. El significado del significado. Una investigación sobre la influencia del lenguaje en el pensamiento y sobre ciencia simbólica. Paidós, Buenos Aires.
Mauro, S. 2009. Identidad, narración y hegemonía en el discurso de los familiares de víctimas de Cromañón. Actas del I Congreso Nacional sobre Protesta social, Acción Colectiva y Movimientos Sociales, UBA-NQUI-UNSAM-INGS, Buenos Aires.

Murillo, S. 2008. Colonizar el dolor. La interpelación ideológica del Banco Mundial en América Latina. El caso argentino desde Blumberg a Cromañón. CLACSO, Buenos Aires.

Needham, R. 1972. Belief, language and experience. Basil Blackwell, Oxford

Noel, Gabriel 2011 La Conflictividad Cotidiana en el Escenario Escolar UNSAM, Buenos Aires.

Pereyra, S. 2005. ¿Cuál es el legado del movimiento de derechos humanos? El problema de la impunidad y los reclamos de justicia en los noventa. Ed. Schuster, F. et. al. Tomar la palabra. Estudios sobre protesta social y acción colectiva en la Argentina contemporánea. Cap. 6, 151-193, Prometeo, Buenos Aires.

Pita, M. V. 2010. Formas de morir y formas de vivir. El activismo contra la violencia policial. Ediciones del Puerto, Buenos Aires.

Sanz Cerbino, G. 2009. Culpable. República Cromañón 30 de diciembre de 2004. Ediciones Razón y Revolución, Buenos Aires.

Schillagi, C. 2006. La obsesión excluyente. Las movilizaciones sociales en torno a la cuestión de la (in)seguridad en Argentina durante el año 2004. Temas \& Debates, n 12, http://www.bdp. org.ar/facultad/publicaciones/tyd/numeros_anteriores/12/Schillagi. pdf (Última consulta: 22/05/2012).

Texeira, C.C. 1998. A honra da política. Decoro parlamentar e cassação de mandato no Congresso Nacional (1949-1994). Relume Dumará. Rio de Janeiro.

Vecchioli, V. 2009 "Expertise jurídica y capital militante: reconversiones de recursos escolares, morales y políticos entre los abogados de derechos humanos en la Argentina" Pro-Posições. Vol.20, n.2, 41-57.

Vecchioli, V. 2004. La constitución de familiares y legisladores como víctimas y profesionales de la política. Actas de las Segundas Jornadas de Investigación en Antropología Social, FFyL-UBA, Buenos Aires.

Zenobi, D. 2014. Familia, política y emociones. Las víctimas de Cromañón entre el movimiento y el Estado. Antropofagia, Buenos Aires. En prensa.

Zenobi, D. 2010. O antropólogo como 'espião. Das acusações públicas à construção das perspectivas nativas. Mana. Estudos de antropologia social, vol. 16, $n^{\circ} 2$, pp. 471-499. 